\title{
Post-Traumatic Stress Constrains the Dynamic Repertoire of Neural Activity
}

\author{
Bratislav Mišić, ${ }^{1}$ Benjamin T. Dunkley, ${ }^{2}$ Paul A. Sedge, ${ }^{3}$ Leodante Da Costa, ${ }^{4}$ Zainab Fatima, ${ }^{5}$ Marc G. Berman, ${ }^{6}$ \\ Sam M. Doesburg, ${ }^{2}$ Anthony R. McIntosh, ${ }^{5}$ Richard Grodecki, ${ }^{7}$ Rakesh Jetly, ${ }^{8}$ Elizabeth W. Pang, ${ }^{2}$ and Margot J. Taylor ${ }^{1}$ \\ ${ }^{1}$ Department of Psychological and Brain Sciences, Indiana University, Bloomington, Indiana 47405, ${ }^{2}$ Department of Diagnostic Imaging, Hospital for Sick \\ Children, Toronto, Ontario M5G 1X8, Canada, ${ }^{3}$ Directorate of Mental Health, Canadian Forces Health Services, Ottawa, Ontario K1K 0T2, Canada, ${ }^{4}$ Division \\ of Neurosurgery, Sunnybrook Hospital, Toronto, Ontario M4N 3M5, Canada, ${ }^{5}$ Research Institute, Baycrest Centre, Toronto, Ontario M6A 2E1, Canada, \\ ${ }^{6}$ Department of Psychology, University of Chicago, Chicago, Illinois 60637, ${ }^{7}$ Canadian Forces Environmental Medicine Establishment, Toronto, Ontario \\ M3K 2C9, Canada, and ${ }^{8}$ Defence Research and Development Canada, Toronto, Ontario N3K 2C9, Canada
}

Post-traumatic stress disorder (PTSD) is an anxiety disorder arising from exposure to a traumatic event. Although primarily defined in terms of behavioral symptoms, the global neurophysiological effects of traumatic stress are increasingly recognized as a critical facet of the human PTSD phenotype. Here we use magnetoencephalographic recordings to investigate two aspects of information processing: inter-regional communication (measured by functional connectivity) and the dynamic range of neural activity (measured in terms of local signal variability). We find that both measures differentiate soldiers diagnosed with PTSD from soldiers without PTSD, from healthy civilians, and from civilians with mild traumatic brain injury, which is commonly comorbid with PTSD. Specifically, soldiers with PTSD display inter-regional hypersynchrony at high frequencies $(80-150 \mathrm{~Hz})$, as well as a concomitant decrease in signal variability. The two patterns are spatially correlated and most pronounced in a left temporal subnetwork, including the hippocampus and amygdala. We hypothesize that the observed hypersynchrony may effectively constrain the expression of local dynamics, resulting in less variable activity and a reduced dynamic repertoire. Thus, the re-experiencing phenomena and affective sequelae in combat-related PTSD may result from functional networks becoming "stuck" in configurations reflecting memories, emotions, and thoughts originating from the traumatizing experience.

Key words: connectivity; dynamics; MEG; network; PTSD; TBI

Significance Statement

The present study investigates the effects of post-traumatic stress disorder (PTSD) in combat-exposed soldiers. We find that soldiers with PTSD exhibit hypersynchrony in a circuit of temporal lobe areas associated with learning and memory function. This rigid functional architecture is associated with a decrease in signal variability in the same areas, suggesting that the observed hypersynchrony may constrain the expression of local dynamics, resulting in a reduced dynamic range. Our findings suggest that the re-experiencing of traumatic events in PTSD may result from functional networks becoming locked in configurations that reflect memories, emotions, and thoughts associated with the traumatic experience.

\section{Introduction}

Post-traumatic stress disorder (PTSD) is an anxiety disorder that manifests in response to a traumatic event that involves an actual

\footnotetext{
Received April 15, 2015; revised 0ct. 1, 2015; accepted Nov. 11, 2015.

Author contributions: B.M., P.A.S., L.D.C., R.G., R.J., E.W.P., and M.J.T. designed research; B.M. performed research; B.M., B.T.D., Z.F., M.G.B., S.M.D., and A.R.M. contributed unpublished reagents/analytic tools; B.M. and A.R.M. analyzed data; B.M., A.R.M., E.W.P., and M.J.T. wrote the paper.

This work was supported by Defense Research and Development Canada (contract \#W7719-135182/001/TOR) and the Canadian Forces Health Services to M.J.T. and E.W.P. and a James S. McDonnell Foundation grant to A.R.M., B.M. was supported by an Natural Sciences and Engineering Research Council of Canada postdoctoral fellowship. The authors declare no competing financial interests.

Correspondence should be addressed to Bratislav Mišic, Department of Psychological and Brain Sciences, Indiana University, 1101 E $10^{\text {th }}$ St., Bloomington, IN 47405. E-mail: bmisic@indiana.edu.
}

or perceived threat of death or injury. The American Psychiatric Association [Diagnostic and Statistical Manual of Mental Disorders, $4^{\text {th }}$ Edition, Text Revision (DSM-IV-TR); American Psychiatric Association, 2000] defines PTSD with respect to three symptom clusters: (1) re-experiencing intrusive memories of the original event, (2) avoidance of stimuli associated with the event, and (3) emotional numbing and hyperarousal. As the number of afflicted veterans from recent missions in Afghanistan and Iraq increases, there is a growing need to understand the disorder, 
both for diagnostic and therapeutic purposes (Garber et al., 2012).

Although PTSD is primarily defined in psychological terms, the neurophysiological effects of traumatic stress are increasingly recognized as an important facet of the PTSD phenotype (Pitman et al., 2012). For instance, exposure to traumatic stress can affect gray matter volume in such structures as the hippocampi (Kitayama et al., 2005), the ventromedial prefrontal cortex (Kasai et al., 2008, and the dorsal anterior cingulate cortex (Kitayama et al., 2006). Patients with PTSD display atypical functional activation in many regions, including the hippocampi (Bremner et al., 2003), the amygdalae (Etkin and Wager, 2007), and the ventromedial prefrontal cortex (Shin et al., 2004; Felmingham et al., 2010). Altogether, these data suggest that PTSD affects multiple aspects of information processing, both locally and globally. In particular, core symptoms of PTSD are thought to originate from a fear-conditioning mechanism, whereby the re-experiencing of traumatic events arises from frequent reactivation of fear circuits. Here we investigate the effect of traumatic stress on two complementary aspects of brain function: the dynamic range of local activity and inter-regional communication.

The inherent variability of neural activity has traditionally been disregarded as "noise" that masks the underlying mean signal. But dynamical systems theory suggests that that is not necessarily the case. Namely, a dynamical system that flexibly responds to external perturbations is capable of multiple metastable states and system configurations (Deco et al., 2009, 2013), resulting in variable activity. Moreover, converging evidence shows that signal variability is a robust indicator of brain function and integrity that is sensitive to engagement in cognitive tasks (Mišić et al., 2010; Heisz et al., 2012; Garrett et al., 2014), clinical disorders (Mizuno et al., 2010; Takahashi et al., 2010; Catarino et al., 2011; Raja Beharelle et al., 2012; Mišíc et al., 2014), and changes across the lifespan (McIntosh et al., 2008, 2014; Garrett et al., 2010, 2011; Vakorin et al., 2011; Yang et al., 2013).

While signal variability is an expression of local system dynamics, the collective function of multiple brain areas can be described in terms of the statistical dependencies between their time courses, termed functional connectivity. Functional connectivity is hypothesized to reflect inter-regional communication and coordinated integrative processing (Friston, 1994; McIntosh and Mišić, 2013). Importantly, several reports using magnetoencephalography (MEG) suggest that traumatic stress affects oscillatory brain activity and patterns of synchrony among distributed brain regions. Temporal areas have been implicated, with increases in slow local oscillations in the insular cortex (Kolassa et al., 2007) and the superior temporal gyrus (James et al., 2013), as well as increased synchrony with other cortical areas, particularly the parietal cortex (Engdahl et al., 2010; Georgopoulos et al., 2010). Converging evidence from seed-based fMRI studies, measuring hemodynamic activity, shows similar hyperconnectivity between temporal sites and the rest of the brain, including connectivity between the posterior cingulate and hippocampus, amygdala, and superior temporal gyrus (Zhou et al., 2012), between the amygdala and insula (Rabinak et al., 2011), and between the amygdala and anterior cingulate cortex (Brown et al., 2014). Previously, we demonstrated that hippocampal synchrony in combat-exposed soldiers with PTSD is associated with increased symptom severity and worse cognitive and affective outcome (Dunkley et al., 2014). Moreover, previous studies suggest that through perpetual interplay between local and global dynamics, signal variability and functional connectivity should be related to each other and provide complementary information about the integrity of the system (Mišić et al., 2011; Deco et al., 2013; Garrett et al., 2013).

\section{Materials and Methods}

The goal of the present study was to investigate the effect of combatrelated traumatic stress on integrative processing in the brain, as measured by signal variability and functional connectivity. To capture the distributed effects of PTSD, we used a novel application of multivariate partial least-squares (PLS) analysis (Berman et al., 2014; Mišić et al., 2014). To capture the effects of PTSD on fast, transient neural activity and to localize these effects to specific frequency bands and brain regions, we used MEG. We analyzed two resting-state recordings before and after triggering: a set of tasks that involved exposure to stressful, combatrelated stimuli. Due to the high comorbidity of traumatic brain injury (TBI) with PTSD, we included two additional control groups: civilians with mild TBI (mTBI) and healthy civilian controls.

Participants. MEG data were recorded from four distinct groups: PTSD soldiers, control soldiers, mTBI civilians, and control civilians. The PTSD soldiers group comprised 23 male Canadian Armed Forces soldiers (mean age, 37.4 years) who had been deployed in support of the Afghan mission and afterwards were diagnosed with PTSD. The control soldiers group comprised 21 male Canadian Armed Forces soldiers (mean age, 33.05 years) who also had been deployed in the Afghan mission but did not develop PTSD.

The PTSD criteria were defined as follows: (1) a diagnosis of combatrelated PTSD by an operational trauma stress support center, (2) PTSD symptoms present 1-4 years before participation in the present study, (3) moderate or greater severity on the PTSD check list (PCL; PCL, > 50). Diagnosis was provided by a military psychiatrist on the basis of a semistructured interview, following DSM-IV-TR diagnostic criteria (American Psychiatric Association, 2000) and Canadian Armed Forces standardized psychometric testing. The clinical interviews revealed that most participants experienced $>1 D S M-I V-T R$ "A1" event that contributed to the development of PTSD (direct personal experience of an event that involves actual or threatened death or injury).

Control soldiers were matched with respect to rank, military experience, handedness, and education level. Both the PTSD and control soldiers were subject to the following inclusion criteria: (1) no history of a TBI (screened by a psychiatrist through a review of electronic health record, telephone interview, and the Defense and Veteran's Brain Injury Centre three-item screening tool), (2) ability to speak English, and (3) ablility to provide informed consent. All PTSD soldiers were taking some form of evidence-based psychotropic medication at the time of data acquisition, including selective serotonin reuptake inhibitors (SSRIs), serotonin norepinephrine reuptake inhibitors (SNRIs), and prazosin, resulting in a naturalistic sample. In other words, the sample of participants was not controlled for presence, type, and dose of psychotropic medication.

The mTBI group comprised 20 male civilian participants ( $<3$ months postinjury; mean period since injury, 32.20 days; mean age at injury, 31.4 years). Participants with mTBI were recruited via the emergency department at the Sunnybrook Health Science Centre in Toronto, Canada. These participants were subject to the following inclusion criteria: (1) between 20 and 40 years of age, (2) concussion symptoms while in the emergency department, (3) $<3$ months since injury, (4) $<30$ min loss of consciousness if loss of consciousness occurred, (4) $<24 \mathrm{~h}$ posttraumatic amnesia if post-traumatic amnesia occurred, (5) clear cause of head injury known, (6) Glasgow Coma Scale $>13$, (7) no skull fracture and unremarkable CT scan, and (8) no previous incidence of concussion.

The civilian control group $(n=21)$ was age-matched and sex-matched (mean age, 27.0 years). This group had no history of TBI (mild, moderate, or severe) or neurological disorders. All participants were Englishspeaking, capable of providing informed consent, and complied with instructions to complete tasks during MEG and MR scans.

For all four groups, exclusion criteria included the following: (1) imbedded ferrous metal that may be classified as MRI contraindications or interfere with MEG data acquisition, (2) implanted medical devices, (3) neurological disorders or substance abuse, (4) ongoing medication known to influence electrical brain activity, including anticonvulsants, 
benodiazepines, and GABA antagonists. None of the participants with PTSD had a history of mTBI, and none of the participants with mTBI had PTSD.

Procedure and MEG data acquisition. Participants lay supine in a magnetically shielded room at the Hospital for Sick Children in Toronto. Two task-free resting-state runs were recorded in the MEG scanner, $\sim 45$ min apart. Participants were instructed to rest with eyes open and to maintain visual fixation on a central point of the screen, marked by an $\mathrm{X}$ within a circle. Upon completion of the first resting-state run, participants completed several other imaging protocols and paradigms. These included the following: (1) a memory task including trigger images, such as visual depictions of the Afghan battlefield, intermixed with neutral images, (2) an inhibition task featuring emotional faces, and (3) an attention task that featured salient trigger words (e.g., "grenade") and neutral words. These affective stimuli and tasks were expected to induce arousal and attentional mechanisms in the soldiers and, as a result, we refer to the first scan as the "pre-trigger" resting-state run and the second scan as the "post-trigger" resting-state run.

MEG data were acquired using a CTF Omega 151-channel system (CTF Systems) at a sampling rate of $600 \mathrm{~Hz}$ for $300 \mathrm{~s}$ and subjected to third-order spatial-gradient environmental-noise cancellation. Head position was continuously recorded by three fiducial coils placed at the nasion and the left and right preauricular points. Following the MEG session, anatomical T1-weighted MRIs were collected using a 3T MRI scanner (Magnetom Tim Trio, Siemens). Images were collected using 3D MPRAGE sequences $\left(\mathrm{TR}=2300 \mathrm{~ms}\right.$; $\mathrm{TE}=2.9 \mathrm{~ms}$; flip angle, $9^{\circ}$; fieldof-view, $28.8 \times 19.2 \mathrm{~cm}$; $256 \times 256$ matrix; 192 slices; $1 \mathrm{~mm}$ isovoxel) and a 12-channel head coil. MEG scans were coregistered to the MRIs using the fiducial coils as a reference. Individual multisphere models were constructed and normalized to the standard Montreal Neurological Institute space using SPM2.

MEG data processing. MEG data time series were bandpass filtered at DC- $150 \mathrm{~Hz}$ and notch filtered at $60 \mathrm{~Hz}$. Sources of interest were selected using the Automated Anatomical Labeling (AAL) atlas (TzourioMazoyer et al., 2002), resulting in 90 cortical and subcortical locations. A vector beamformer (described below) was then used to reconstruct time series from these locations (termed "virtual sensors") for each individual participant. The time series were then further filtered into five classical bands for further analysis: theta $(4-7 \mathrm{~Hz})$, alpha $(8-14 \mathrm{~Hz})$, beta $(15-30$ $\mathrm{Hz})$, "low" gamma $(30-80 \mathrm{~Hz})$, and "high" gamma $(80-150 \mathrm{~Hz})$.

Beamformers are 3D adaptive spatial filters that use surface field measurements to estimate activity at particular sources in the brain while simultaneously suppressing noise from other sources. In the present study, the sources of interest were derived from the AAL atlas, as described above. Activity at each target source was estimated as a weighted sum of surface field measurements (Quraan and Cheyne, 2010). The weights themselves, as well as the orientation of source dipoles, were optimized in a least-squares sense, wherein the average power originating from all other sources was maximally attenuated without any decrease in the power of the forward solution for the source of interest. MEG beamformers have been shown to be effective at suppressing ocular and nonocular artifacts, including cardiac and muscle activity (Muthukumaraswamy, 2013), obviating further artifact correction.

For the past two decades, a body of empirical evidence has accumulated demonstrating the ability of MEG to detect weak signals emanating from deep brain structures, such as the hippocampus (Kirsh et al., 2003; Hamada et al., 2004; Cornwell et al., 2008a), amygdalae (Cornwell et al., 2007, 2008b, 2010; Luo et al., 2007; Hung et al., 2012), and thalamus (Bish et al., 2004; Bardouille and Ross, 2008). Moreover, several studies based on physiologically realistic simulations (Attal and Schwartz, 2013; Balderston et al., 2013)—some using CTF Systems machines (Quraan et al., 2011; Mills et al., 2012) — have demonstrated the ability of beamformer or minimum variance current estimate solutions to localize deep generators.

We chose the AAL atlas to guide the beamforming procedure for several reasons. First, the AAL atlas provides parcels (in the present case, sources) for all brain regions that have previously been implicated in PTSD, including the hippocampi, amygdalae, superior temporal gyri, insulae, and anterior cingulate. Second, the AAL atlas is among the most frequently used references in the PTSD literature, making the present results readily comparable to those of previous studies. An important methodological consideration is that this nonvolumetric approach may potentially miss important individual connections between brain regions that are not near a source. In the present study, this drawback was minimized because we focused on global multivariate effects of posttraumatic stress, but this consideration highlights the need for deriving anatomically and functionally representative multiscale parcellations of the human brain.

Functional connectivity: weighted phase lag index. Functional connectivity between band-limited source time series was estimated using the weighted phase lag index (wPLI; Vinck et al., 2011). The instantaneous phase of each time point in the filtered source time series was calculated using the Hilbert transform. The Hilbert-transformed time series were then used to estimate phase synchronization between all pairs of sources. Specifically, we calculated the wPLI as the magnitude of the imaginary component of the cross-spectrum (Lau et al., 2012). The wPLI was chosen over other similar measures of synchrony as the phase-locking value or imaginary coherence primarily because it has been shown to be more robust against spurious volume-conducted neural synchrony (Vinck et al., 2011). In addition, the present report builds on an existing body of literature showing that wPLI is effective in distinguishing abnormal resting oscillatory synchrony in clinical populations (Boersma et al., 2013; Dimitriadis et al., 2013; Ibrahim et al., 2014; Ye et al., 2014).

Signal variability: multiscale entropy. The goal of multiscale entropy (MSE) analysis is to estimate the variability of a time series at multiple temporal scales (Costa et al., 2002, 2005). Each time series is downsampled to multiple, coarse-grained time scales and sample entropy $\left(S_{\mathrm{E}}\right)$ is calculated for each scale (Richman and Moorman, 2000). The downsampling procedure is performed for several scales $\tau$. A coarse-grained time series for scale $\tau$ is calculated from the original time series by averaging data points in nonoverlapping windows of length $\tau$ (thus, $\tau=1$ corresponds to the original time series). For convenience, time scales can be expressed in seconds by dividing the scale $\tau$ by the sampling rate $(600 \mathrm{~Hz})$.

For each downsampled time series, the $S_{\mathrm{E}}$ algorithm is used to estimate the conditional probability that any two sequences of $m+1$ data points will be similar to each other given that they were similar for the first $m$ points, effectively quantifying the regularity or predictability of the time series. The $S_{\mathrm{E}}$ metric is the negative of the natural logarithm of this quantity, such that regular, predictable time series are assigned small $S_{\mathrm{E}}$ values, while variable, unpredictable time series are assigned large $S_{\mathrm{E}}$ values.

The MSE procedure depends on two parameters: the pattern length $m$, which determines the length of sequences used to estimate $S_{\mathrm{E}}$, and the similarity $r$, which is the criterion for assessing similarity between sequences. In the present study, pattern length was set to $m=2$ and the similarity criterion to $r=0.5$. The pattern length (also known as the embedding dimension) was judged to be optimal following the method proposed by Small and Tse (2004), which uses an information theoretic criterion for determining the optimal embdedding dimension in terms of the ability of the dimension to capture the inherent periodicity in the signal with respect to a predictive dynamic model. The similarity criterion (also known as the tolerance) was chosen following the procedure described by Richman and Moorman (2000), which was to set the tolerance to 0.5 times the SD of the signal. In the present study, the source time series were normalized to have zero mean and unit SD and, as a result, the tolerance was set to 0.5 .

Oscillatory power: power spectral density. Several reports have indicated that changes in the dynamic range of neural signals often reflect changes in power spectral density (PSD), offering complementary information (McIntosh et al., 2008; Mišić et al., 2014). Likewise, it is possible changes in interareal phase synchrony depend on changes in local oscillatory power. To investigate the extent to which changes in synchrony or local signal variability depend on changes in spectral properties of the signal, we computed PSD for all source time series. To account for individual differences in global signal power, all time series were normalized to a mean of 0 and an SD of 1 . Power spectra were computed using the fast Fourier transform. At the present sampling rate $(600 \mathrm{~Hz})$ and number of time points $(180,000)$, the frequency resolution of the analysis was 0.0025 
Hz. Power spectral density was estimated at the same classical frequency bands used in the synchrony analysis (see above).

Statistical assessment: PLS. PLS analysis is a multivariate statistical technique that serves to relate two blocks of variables to one another (McIntosh and Lobaugh, 2004; McIntosh and Mišić, 2013). In most neuroimaging applications, these blocks correspond to the study design on one hand (e.g., the assignment of groups and/or conditions) and neural activity on the other (e.g., electromagnetic activity, hemodynamic activity, etc.). The principal feature of PLS is the ability to analyze multivariate datasets, where one or both blocks contain data that vary across multiple dimensions (e.g., electromagnetic activity across multiple sources and time points; hemodynamic activity across multiple voxels and time points). The goal of the analysis is to find linear combinations of variables in both blocks that maximally covary with each other (e.g., a combination of groups and/or conditions that may be interpreted as a contrast, together with a spatiotemporal pattern of sources and time points that covary with that contrast).

In the present study, we used two different types of neural activity data blocks, which are represented as the matrix X. In both analyses, the matrix X is arranged such that the observations (participants nested within conditions, nested within groups) correspond to the rows of the matrix, and the variables to the columns of the matrix. To investigate the effect of PTSD on signal variability, we analyzed MSE data, such that the columns of the matrix correspond to time scales nested within sources. To investigate the effect of PTSD on functional connectivity, we analyzed the wPLI data, such that the columns of the matrix correspond to the unique entries (upper diagonal) of the wPLI matrix.

The data matrix $\mathrm{X}$ is used to create a matrix of means, $\mathrm{M}$, by calculating column-wise means within each group or task. If there are $g$ groups, $c$ conditions, and $v$ variables, $\mathrm{M}$ has $g \times c$ rows and $v$ columns. To potentiate group differences, the grand condition means are then removed from each condition. Alternatively, to potentiate condition differences, the group condition means are removed from each group. The resulting mean-centered matrix, $M_{d e v}$, has the same dimensions as $M$, and is subjected to singular value decomposition (SVD) according to the following equation: $[\mathrm{U}, \mathrm{S}, \mathrm{V}]=\operatorname{SVD}\left(\mathrm{M}_{\mathrm{dev}}\right)$ such that $\mathrm{USV}^{\prime}=\mathrm{M}_{\mathrm{dev}}$.

The outcome of a PLS analysis is a set of mutually orthogonal latent variables. The number of latent variables is equal to the rank of $M_{\text {dev }}$, which is the smaller of its dimensions (typically $g \times c$ for most neuroimaging experiments). Accordingly, $\mathrm{U}$ has $v$ rows and $g \times c$ columns, $\mathrm{V}$ has $g \times c$ rows and $g \times c$ columns, and S also has $g \times c$ rows and $g \times c$ columns. Each latent variable is composed of a set of singular vectors (columns of $\mathrm{U}$ and $\mathrm{V}$ ) and a set of singular values (diagonal elements of S).

The singular vectors are weights that describe the contributions of variables from the original data blocks to the overall multivariate pattern. The column vectors of $\mathrm{U}$ contain $r$ elements (e.g., sources or functional connections) describing the weighting of the original imaging variables in the latent variable, and can be interpreted as functional networks or spatiotemporal patterns. The column vectors of $\mathrm{V}$ contain $g \times c$ elements (e.g., groups and conditions) describing the weighting of the design variables in the latent variable, and can be interpreted as a contrast. Finally, each latent variable is associated with a scalar singular value from the diagonal matrix $S$, which reflects the covariance between the two data blocks captured by the latent variable. The effect size (proportion of cross-block covariance) of a latent variable can be estimated as the ratio of the squared singular value to the sum of squared singular values from the decomposition.

The statistical significance of a latent variable is assessed by permutation testing, while the reliability of individual weights is estimated by bootstrapping. Permutation tests are performed by randomly reordering the rows of the original data matrix $X$, generating a set of permuted data matrices where the original group and condition assignments have been destroyed. The permuted data matrices are mean-centered and subjected to SVD as described above, to generate a distribution of singular values under the null hypothesis that there is no relation between the brain data block and the design block. Since the singular values are proportional to the magnitude of a statistical relationship captured by a latent variable, a $p$ value for a latent variable is estimated as the proportion of times the permuted singular values exceed the original singular value. Note that statistical inference is made at the level of the entire multivariate pattern, rather than at the level of individual variables. As a result, only a single test is performed and further correction for multiple comparisons is not warranted.

Bootstrapping is performed by randomly resampling participants with replacement (i.e., the rows of data matrix X), while respecting the original group and condition assignments (Efron and Tibshirani, 1986). The resampled data matrices are mean-centered and subjected to SVD as described above, to generate a sampling distribution for each of the weights in the singular vectors. The bootstrap distribution is used to estimate the SE for each weight, which reflects the stability of the weight. Finally, a bootstrap ratio is calculated for each original variable (e.g., functional connection or source), by dividing the weight from the singular vector by its bootstrap-estimated SE. Thus, a bootstrap ratio with a large magnitude indicates that the functional connection or source with which it is associated has both a large singular vector weight (i.e., contributes to the latent variable) and a small SE (i.e., stable across participants). When the bootstrap distribution is approximately normal, the bootstrap ratio is equivalent to a $z$-score (Efron and Tibshirani, 1986). Thus, bootstrap ratio maps are thresholded at values of \pm 2.58 , corresponding to the $99 \%$ confidence interval.

\section{Results}

\section{High-frequency hypersynchrony}

We measured spontaneous inter-regional phase synchrony (functional connectivity) using the wPLI, resolved in five classical frequency bands: theta $(4-7 \mathrm{~Hz})$, alpha $(8-14 \mathrm{~Hz})$, beta (15-30 $\mathrm{Hz})$, low gamma $(30-80 \mathrm{~Hz})$, and high gamma $(80-150 \mathrm{~Hz})$. To assess the effects of PTSD and mTBI on functional connectivity, we treated each of the elements of the wPLI matrix (i.e., functional connections) as separate variables in the PLS analyses. Configured in this way, the PLS analyses look for combinations of groups and conditions (interpreted as contrasts) that maximally covary with a weighted pattern of functional connections (interpreted as functional networks).

\section{Condition differences}

To assess the effect of the triggering procedure, we meancentered the data using group-specific means, thereby potentiating condition effects (see Materials and Methods). When all four groups are entered into the analysis, no statistically significant effects are found. However, when the analysis is focused only on soldiers with PTSD and the control soldiers, a statistically significant latent variable emerges (Fig. $1 a ; p<10^{-10}$, accounting for $63 \%$ of covariance). The contrast primarily differentiates the pretrigger and post-trigger recordings, but also captures a condition $\times$ group interaction, whereby the effect of the triggering procedure-as revealed by the contrast between pre-trigger and post-trigger scans-is greater in the control compared with the PTSD soldiers (Fig. 1a).

Figure $1 b, c$ shows the expression of the latent variable across all connections and frequency bands, as indexed by bootstrap ratios. Bootstrap ratios are used to estimate how reliably a particular connection expresses the contrast shown in Figure $1 a$, and can be interpreted as a $z$-score (see Materials and Methods). Connections with positive bootstrap ratios express the contrast as is, while connections with negative bootstrap ratios express the opposite contrast. Thus, the triggering protocol appears to primarily affect functional networks in the low and high gamma bands, spanning frontal and anterior temporal cortices (Fig. 1c; left hippocampus, left parahippocampal gyrus, left operculum, left superior temporal gyrus, left amygdala). The cognitive and affective mechanisms elicited by the triggering procedure induce increased synchrony in these networks, as evident from the exclu- 
a

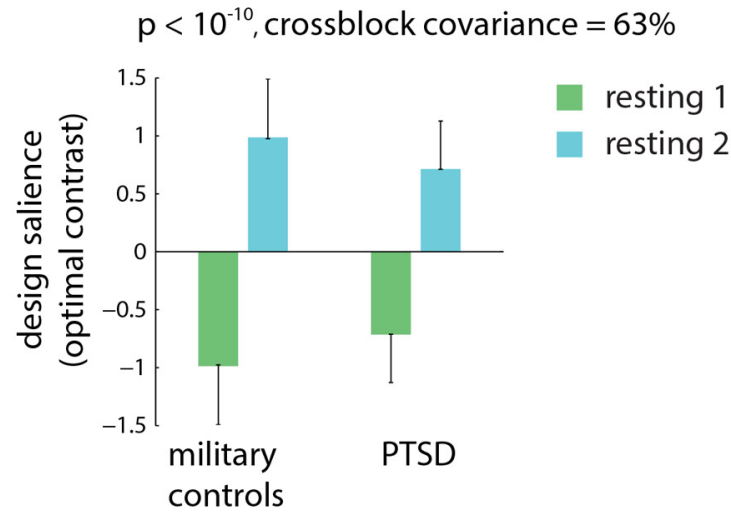

C
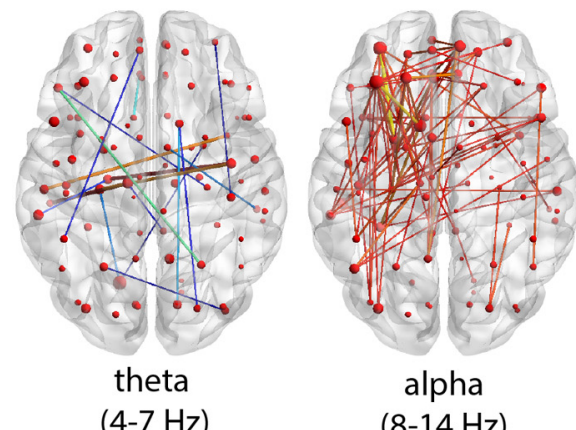

$(8-14 \mathrm{~Hz})$

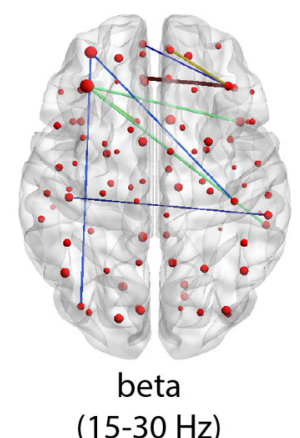

$(15-30 \mathrm{~Hz})$ b

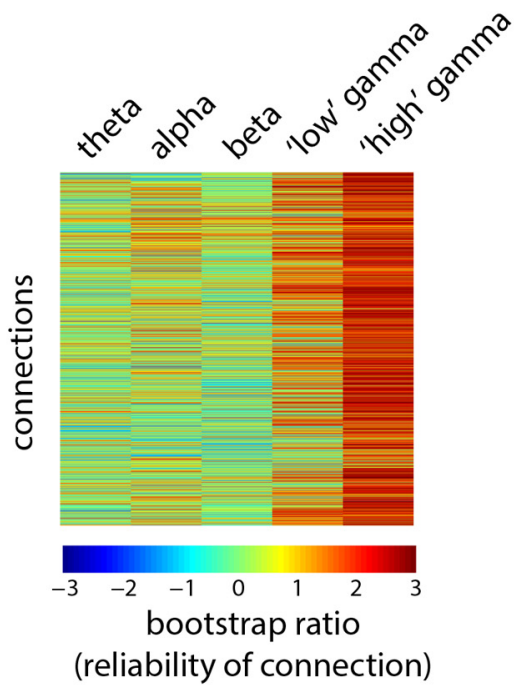

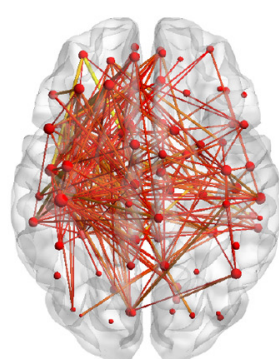

'high' gamma

$(80-150 \mathrm{~Hz})$

bootstrap ratios

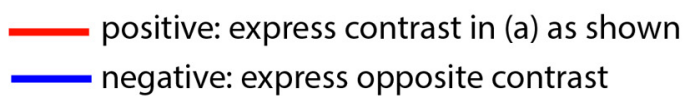

Figure 1. Functional connectivity: condition differences. The dominant PLS latent variable, capturing the effect of triggering on resting-state functional connectivity (measured by the wPLI) in multiple frequency bands in the two military groups. $\boldsymbol{a}$, The optimal combination of groups and conditions (contrast). Error bars represent bootstrap-estimated $95 \%$ confidence intervals. $\boldsymbol{b}$, Bootstrap ratios: a linear combination of connections (i.e., a network) weighted by how reliably they contribute to the latent variable. For a given connection, a high-magnitude positive bootstrap ratio indicates that the connection reliably expresses the contrast in $\boldsymbol{a}$. A high-magnitude negative bootstrap ratio indicates that the connection expresses the opposite contrast. $\boldsymbol{c}$, Statistical maps showing networks of connections that reliably express the contrast in $\boldsymbol{a}$, as determined by bootstrapping (see Materials and Methods).

sively positive bootstrap ratios. This is consistent with results from a subset of these data reported using the network-based statistic approach (Dunkley et al., 2014). Out of all other possible pairwise group comparisons (PTSD vs mTBI, PTSD vs civilian controls, military controls vs mTBI, military controls vs civilian controls, mTBI vs civilian controls), only one was statistically significant: the contrast between PTSD and mTBI. This contrast is explored in more detail in the following subsection.

\section{Group differences}

To assess group effects, we mean-centered the data using condition-specific means, thereby potentiating group differences (see Materials and Methods). The analysis yielded one statistically significant latent variable (Fig. $2 a ; p<10^{-10}$, accounting for $31 \%$ of covariance). The latent variable differentiates the two military groups (PTSD and control soldiers) from the two civilian groups (mTBI and civilian controls), with a pronounced contrast between the PTSD and mTBI groups.

The bootstrap ratio maps indicate that this differentiation of groups was primarily driven by functional networks in the alpha, gamma, and high-gamma bands (Fig. 2b,c). A subnetwork of gamma and high-gamma band connections, comprising the superior temporal sulcus, the supramarginal gyrus, and the temporal pole, displayed stronger synchrony in the PTSD group compared with the mTBI group. Conversely, a subnetwork of alpha band connections, comprising the left superior parietal cortex, the left superior frontal gyrus, and the left precuneus, displayed stronger synchrony in the mTBI group compared with the PTSD group (Fig. 2c). Note also that soldiers with PTSD, compared with control soldiers, displayed greater synchrony in the high-gamma band. Thus, the fact that soldiers with PTSD show a milder reaction to trauma-related cuing (explored in the previous subsection; Fig. 1) may be interpreted as an effect of elevated baseline synchrony.

\section{Narrow dynamic range}

We next investigated the effects of PTSD and mTBI on local signal variability. For each source time series, we estimated signal variability in terms of sample entropy at multiple time scales. 
a

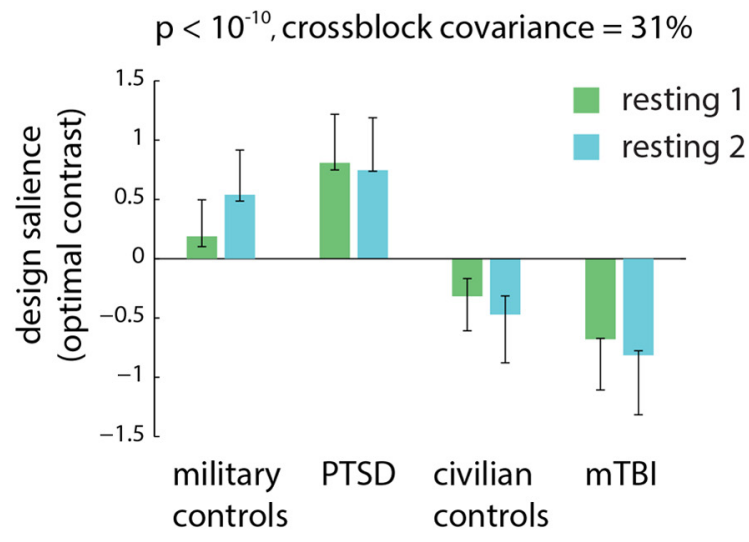

\section{c}

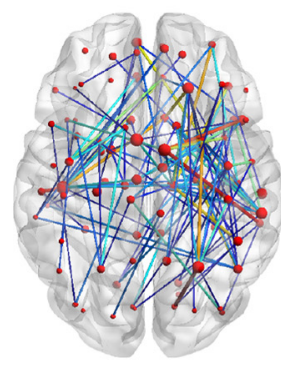

theta

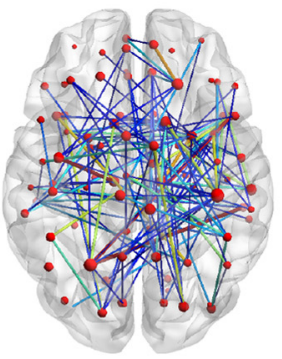

alpha

$(8-14 \mathrm{~Hz})$

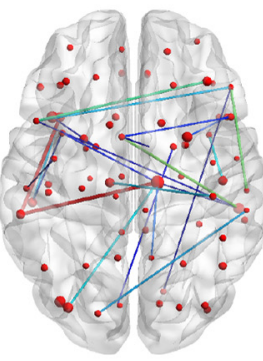

beta b

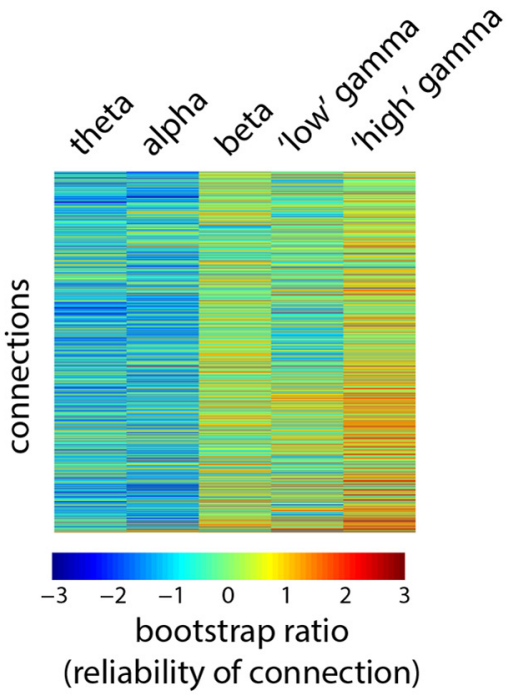

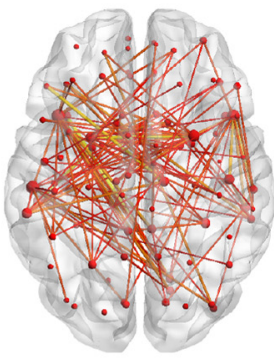

'high' gamma

(80-150 Hz)

bootstrap ratios

positive: express contrast in (a) as shown

negative: express opposite contrast

Figure 2. Functional connectivity: group differences. The dominant PLS latent variable, capturing the effect of group membership on resting-state functional connectivity (measured by the wPLI) in multiple frequency bands. $\boldsymbol{a}$, The optimal combination of groups and conditions (contrast). Error bars represent bootstrap-estimated $95 \%$ confidence intervals. $\boldsymbol{b}$, Bootstrap ratios: a linear combination of connections (i.e., a network), weighted by how reliably they contribute to the latent variable. For a given connection, a high-magnitude positive bootstrap ratio indicates that the connection reliably expresses the contrast in $\boldsymbol{a}$. A high-magnitude negative bootstrap ratio indicates that the connection expresses the opposite contrast. $c$, Statistical maps showing networks of connections that reliably express the contrast in $\boldsymbol{a}$, as determined by bootstrapping (see Materials and Methods).

Using PLS, we captured combinations of sources and time scales at which signal variability was affected by group membership and/or the triggering procedure.

\section{Condition differences}

To determine whether the triggering protocol had any effect on signal variability, we mean-centered the data using groupspecific means. The analysis revealed no statistically significant latent variables. However, the strongest latent variable-as measured by the proportion of covariance that it accounted for-was close to significance at the $5 \%$ level, and for completeness we include it here (Fig. $3 a$; $p=0.06$, accounting for $55 \%$ of covariance). Note, however, that the latent variable is not significant at the conventional alpha threshold of $5 \%$, indicating insufficient evidence to reject the null hypothesis that the effect is significantly different from chance. As such, this particular effect should be interpreted with caution. The latent variable captures a contrast between the pre-trigger and post-trigger resting-state runs and resembles the contrast obtained for functional connectivity (Fig. 1a). Namely, the military controls are affected by the proto- col more than the soldiers with PTSD, as evident from the relative differences in the contrasts for the two groups. Moreover, exposure to trauma-related stimuli had no effect on either civilian group.

Inspection of the bootstrap ratios suggests that exposure to the experimental protocol resulted in lowered signal variability. In addition, these effects were reliably expressed at coarse time scales (Fig. 3b), which correspond to lower frequencies (see Materials and Methods for more information on converting time scales to frequencies). Figure $3 c$ shows the sources where signal variability was reduced due to the protocol for one representative time scale (scale 15, equivalent to $25 \mathrm{~ms}$ ). This condition-induced reduction in signal variability was reliably observed in several temporal structures bilaterally, including the hippocampi, parahippocampal gyri, and amygdalae, as well as ventral frontal structures, including orbitofrontal and anterior cingulate cortices (Fig. 3c).

\section{Group differences}

We next examined whether overall patterns of signal variability differed between groups. PLS analysis revealed a single significant latent 
a

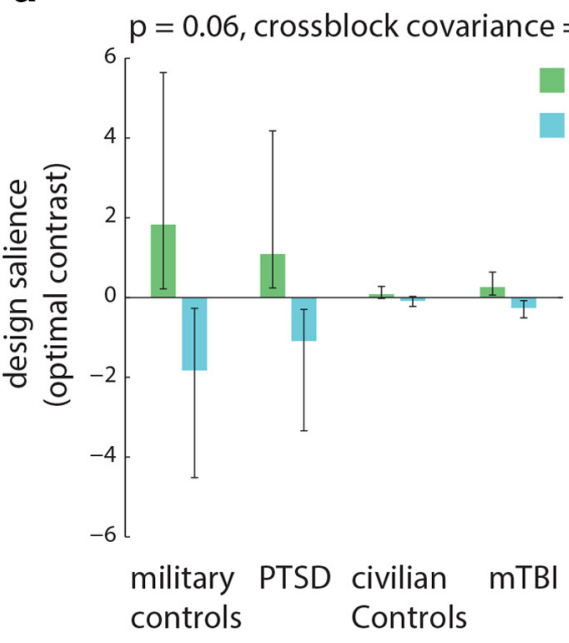

C
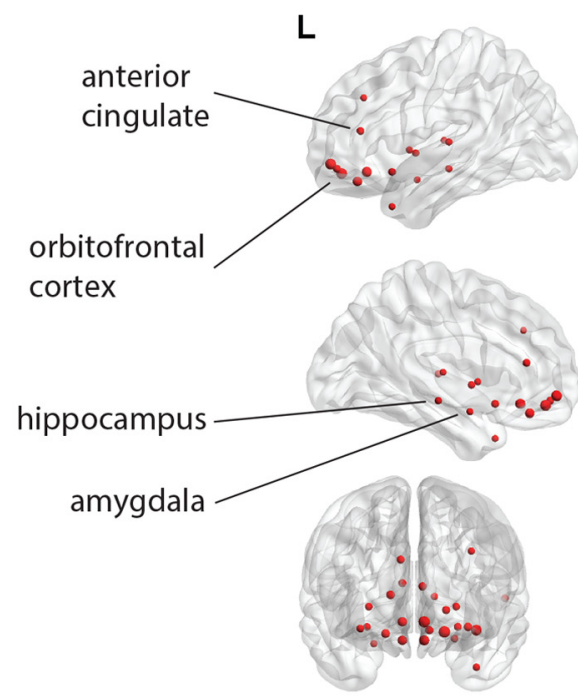

b

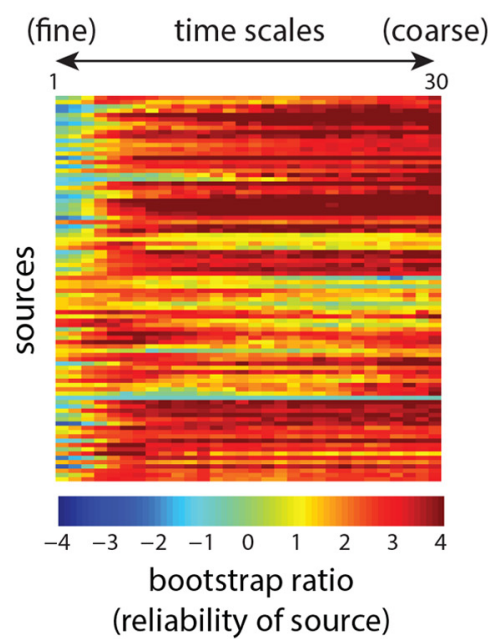

$\mathbf{R}$
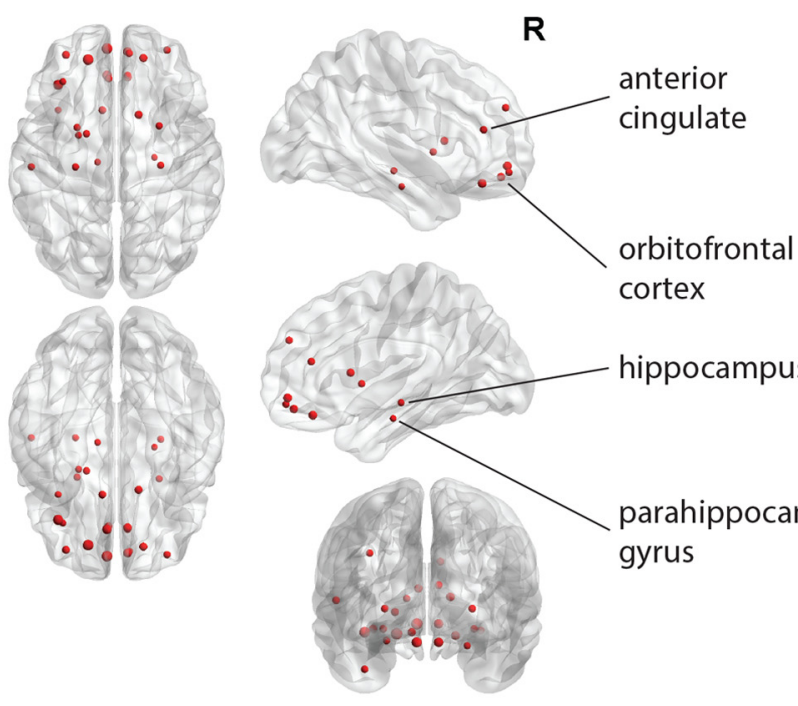
cortex hippocampus gyrus parahippocampal

time scale 15 (=25 ms)

\section{bootstrap ratios}

- positive: express contrast in (a) as shown

- negative: express opposite contrast

Figure 3. Signal variability: condition differences. The dominant PLS latent variable, capturing the effect of triggering on resting-state signal variability at multiple time scales (measured by MSE). $\boldsymbol{a}$, The optimal combination of groups and conditions (contrast). Error bars represent bootstrap-estimated $95 \%$ confidence intervals. Note that, at $p=0.06$, this latent variable is not statistically significant at the conventional statistical alpha threshold of 0.05 . $\boldsymbol{b}$, Bootstrap ratios: a linear combination of sources and time scales (i.e., a spatiotemporal pattern), weighted by how reliably they contribute to the latent variable. For a given source, a high-magnitude positive bootstrap ratio indicates that the source reliably expresses the contrast in $\boldsymbol{a}$. A high-magnitude negative bootstrap ratio indicates that the source expresses the opposite contrast. c, Statistical maps showing sources that reliably express the contrast in $\boldsymbol{a}$, as determined by bootstrapping (see Materials and Methods).

variable (Fig. $4 a ; p=0.04$, accounting for $75 \%$ of covariance) that primarily differentiated the PTSD group from all other groups. In addition, these group differences were more pronounced for the post-trigger resting-state recordings, consistent with the condition analysis shown in the previous subsection (Fig. 3).

The subsequent bootstrap analysis revealed two distinct patterns contributing to these group differences (Fig. $4 b$ ). Namely, a subnetwork of sources, comprising posterior cortical regions and operating mainly at fine time scales, displayed greater signal variability in the PTSD group compared with the other groups. Conversely, a subnetwork of sources, mainly comprising left temporal structures and operating at coarse time scales, displayed lower signal variability in the PTSD group compared with the other groups. Figure $4 c$ shows two representative spatial patterns, one for fine scales and the other for coarse scales.

\section{Functional connectivity and signal variability}

Finally, we observed a remarkable similarity between the patterns of condition-based changes in functional connectivity (Fig. 1c) and signal variability (Fig. $3 c$ ), as well as the similarity in the contrasts associated with those analyses (Figs. $1 a, 3 a$ ). Thus, we directly compared the two bootstrap patterns, focusing on 
a

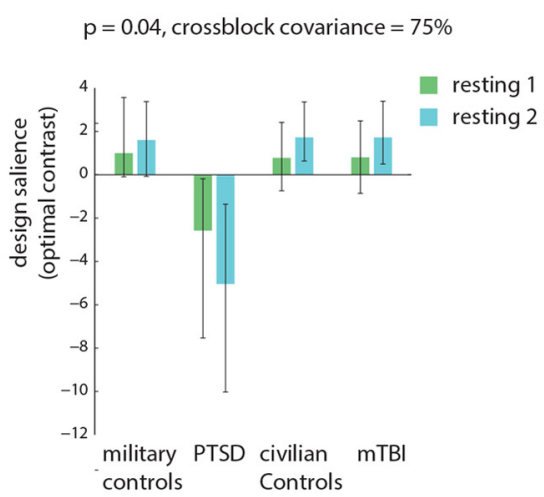

C

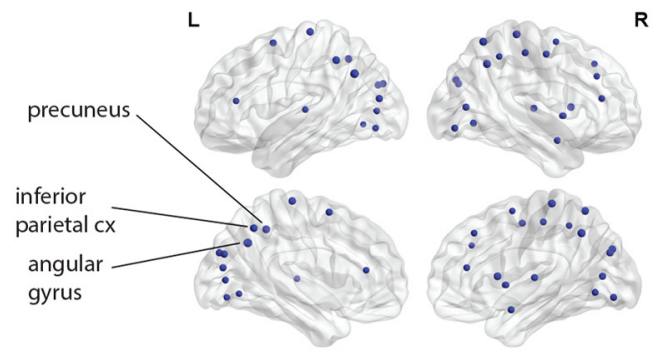

time scale 5 (=9 ms)
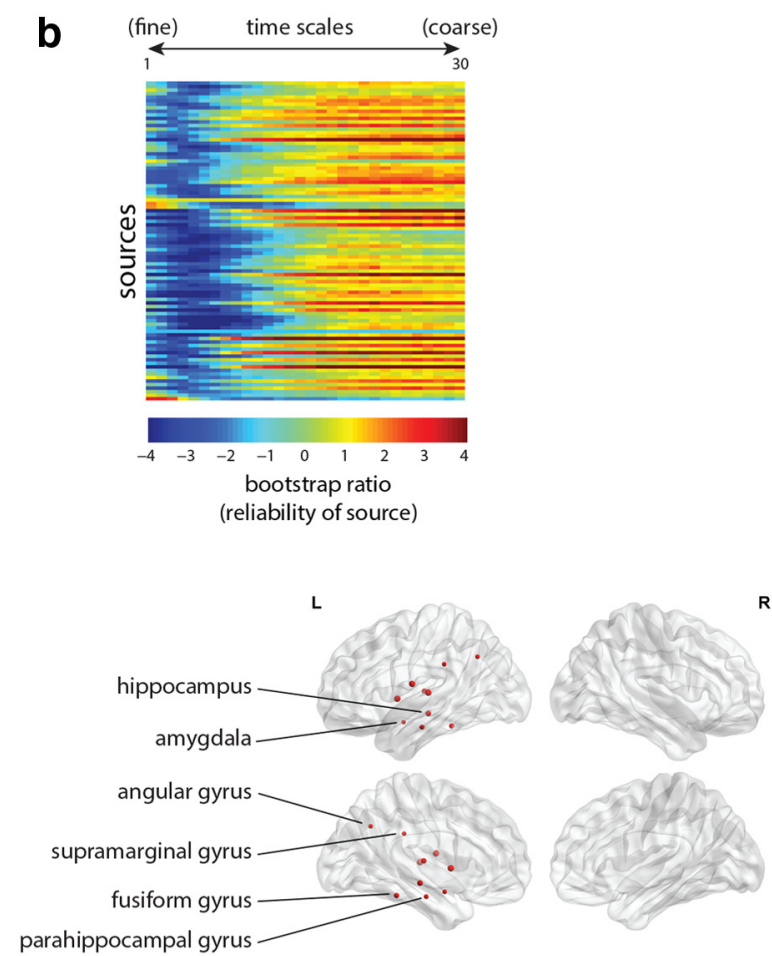

time scale 20 (=33 ms)

bootstrap ratios

- positive: express contrast in (a) as shown

- negative: express opposite contrast

Figure 4. Signal variability: group differences. The dominant PLS latent variable, capturing the effect of group membership on resting-state signal variability at multiple time scales (measured by MSE). $\boldsymbol{a}$, The optimal combination of groups and conditions (contrast). Error bars represent bootstrap-estimated $95 \%$ confidence intervals. $\boldsymbol{b}$, Bootstrap ratios: a linear combination of sources and time scales (i.e., a spatiotemporal pattern), weighted by how reliably they contribute to the latent variable. For a given source, a high-magnitude positive bootstrap ratio indicates that the source reliably expresses the contrast in $\boldsymbol{a}$. A high-magnitude negative bootstrap ratio indicates that the source expresses the opposite contrast. c, Statistical maps showing sources that reliably express the contrast in $\boldsymbol{a}$, as determined by bootstrapping (see Materials and Methods).

condition-dependent increases in functional connectivity and condition-dependent decreases in signal variability. To make the patterns comparable in a temporal sense, we selected functional connectivity patterns at $75 \mathrm{~Hz}$ and signal variability patterns at time scale 8 , both of which correspond to a period of $13.3 \mathrm{~ms}$ given the $600 \mathrm{~Hz}$ sampling rate.

Figure $5 a$ shows the spatial overlap in the bootstrap ratios for the two analyses, revealing a broad correspondence: areas that experience increased synchrony also tend to become less variable. To test this formally, we first estimated the mean change in functional connectivity for every source by calculating the mean bootstrap ratio for every source. We then correlated the mean functional connectivity bootstrap ratios (representing the mean increase in synchrony per node) with the signal variability bootstrap ratios (representing the decrease in signal variability per node). Figure $5 b$ shows that there is a statistically significant, though modest, relation between changes in functional connectivity and signal variability $(r=0.23, p=0.03)$. Upon closer visual inspection, however, it appears that the effect is not global, but driven by a subset of regions, mainly in the left temporal lobe, that experience both increased functional connectivity and decreased signal variability. We confirmed this hypothesis quantitatively: when these 10 data points are removed, the relationship ceases to be statistically significant $(r=0.12, p=0.61)$.

\section{Oscillatory power}

To determine the extent to which changes in synchrony and signal variability depend on changes in oscillatory power, we ana- lyzed the effect of condition and group membership on local PSD at each of the 90 sources. The power spectra produced a statistically significant group effect $\left(p<10^{-10}\right.$, accounting for $60 \%$ of cross-block covariance). The latent variable mainly differentiated the PTSD group from the mTBI group (Fig. 6a), with the PTSD group characterized by greater power in the lower-gamma range (30-80 Hz; left superior temporal gyrus, left pars orbitalis, left parahippocampal gyrus, left and right rectus gyrus), and the mTBI group characterized by greater power in the alpha range (8-14 Hz; left and right anterior cingulate, left angular gyrus, left middle frontal gyrus, and left inferior parietal cortex). This pattern bears some similarity to the group differences observed for synchrony, where the PTSD group was characterized by greater synchrony at higher frequencies and lower synchrony at lower frequencies. However, one important difference between the two effects is the frequency band specificity. While differences in spectral density are most prominent in the lower-gamma range $(30-80 \mathrm{~Hz})$, differences in synchrony are observed at a higher range $(80-150 \mathrm{~Hz})$. Although the effects of post-traumatic stress on local power and synchrony do not overlap completely, these results suggest that the two measures provide complementary information about these clinical populations.

\section{Discussion}

We investigated the effects of traumatic stress on two complementary aspects of brain function and integrity: functional connectivity and signal variability. Soldiers with PTSD experience 
a
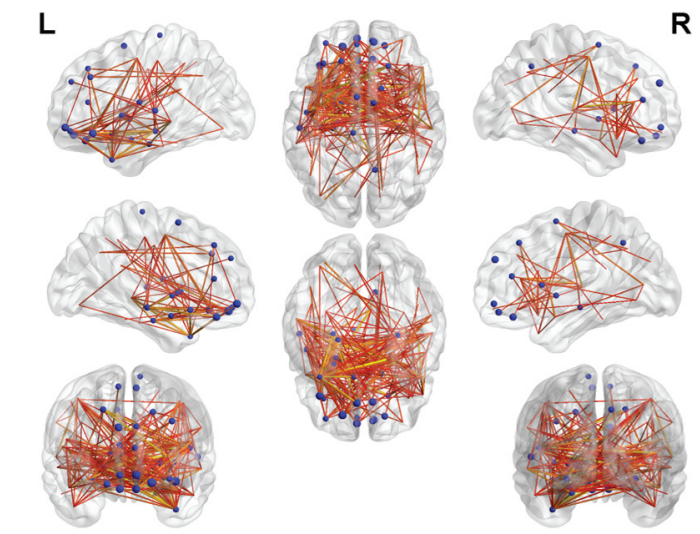

$\mathbf{R}$

b

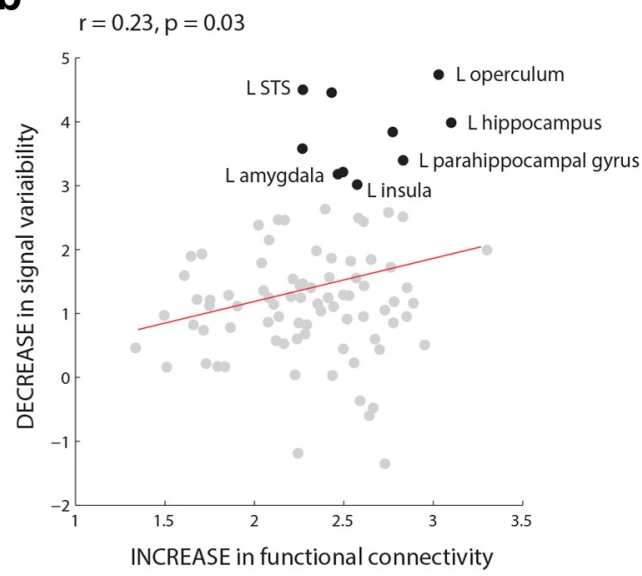

- DECREASE in signal variability (time scale $8=13.3 \mathrm{~ms}$ )

- INCREASE in functional connectivity $(75 \mathrm{~Hz}=13.3 \mathrm{~ms})$

Figure 5. Relation between functional connectivity and signal variability. The overlap between PLS latent variables for functional connectivity and signal variability. $\boldsymbol{a}$, Overlap between the connections that become stronger post-trigger (at $75 \mathrm{~Hz}$, corresponding to a $13.3 \mathrm{~ms}$ period) and sources that become less variable post-trigger (at time scale 8 , corresponding to a $13.3 \mathrm{~ms}$ period). Reliability is assessed by bootstrap analysis (see Materials and Methods). $\boldsymbol{b}$, Correlation between bootstrap ratios for the signal variability analysis, and bootstrap ratios for the functional connectivity analysis, averaged across connections, such that each data point represents a source.

global hypersynchrony at higher frequencies and reduced local signal variability at comparable time scales, relative to matched military controls. Importantly, the two effects appear to be closely related and primarily driven by a left temporal subnetwork, including the hippocampus and amygdala. Altogether, the present findings demonstrate that global connectivity patterns and local signal variability can be used to reliably distinguish PTSD from $\mathrm{mTBI}$. This is a distinction with practical significance, because the two conditions are frequently comorbid-particularly in military personnel—yet require different types of treatment (Bryant, 2011).

We find that soldiers with PTSD consistently display a reduced reaction to the triggering protocol compared with healthy control soldiers. In agreement with previous literature, our results suggest that exposure to stimuli or triggers related to the original trauma may elicit mechanisms related to the disorder and help reveal more about the underlying pathophysiology (Dunkley et al., 2014). Interestingly, most previous literature suggests that reactivity to trauma-related cues, including autonomic reactivity (Pitman et al., 1987; Keane et al., 1998) and potentiated startle (Pole, 2007), is exaggerated in the disorder, while electrical brain activity, such as P3b amplitude, is often reduced (Orr and Roth, 2000). Our analyses suggest that, as a result of elevated baseline synchrony (Fig. 2) and lower baseline variability (Fig. 4), exposure to trauma-related cues does not affect soldiers with PTSD as much as control soldiers. We hypothesize that the state of chronic hyperarousal and re-experiencing of traumatic events in PTSD effectively keeps the soldiers with PTSD at ceiling, whereas the combat-exposed non-PTSD soldiers are temporarily more affected by the triggering protocol.

Likewise, our results suggest that the dynamic range of neural activity is effectively constrained by traumatic stress. Though traditionally considered to be a confound or simple "noise," signal variability is increasingly recognized as a characteristic of functional integration in the brain (Mišić et al., 2011; Garrett et al., 2013), and thus a potential marker of pathology as well. Several recent studies have demonstrated the utility of signal variability as a measure of pathology in clinical populations, including schizophrenia (Brookes et al., 2015), autism spectrum disorder
(Catarino et al., 2011; Mišić et al., 2015), and Alzheimer's disease (Mizuno et al., 2010). Our results contribute to this effort by showing that traumatic stress limits the dynamic range of neural activity in a specific temporal lobe circuit.

Most importantly, evidence from connectivity, signal variability, and triggering collectively suggests a specific mechanism underlying PTSD: global hypersynchrony at higher frequencies may effectively constrain the number of potential states of the system, resulting in stereotyped local signals with low variability. This type of mechanism would be predicted by dynamical systems theory (Deco et al., 2009, 2013), and to our knowledge this is among the first empirical observations of such a mechanism in the context of brain function. The fact that hypersynchrony and the concomitant decrease in variability were particularly severe in a subnetwork of temporal lobe structures, including the hippocampus and amygdala, suggests that this increasingly constrained neural functioning may be related to such symptoms as re-experiencing of memories, emotional reactivity, impaired extinction, and increased sensitivity to stimulation (Pitman et al., 2012).

We thus speculate that network hypersynchrony and stereotyped local dynamics, which characterize the PTSD group, reflect a reduced propensity for exploring the full repertoire of network states and configurations. Moreover, this reduced dynamic repertoire may reflect a predisposition for occupying states that contribute to the symptoms and cognitive sequelae associated with PTSD. A prominent view in computational neuroscience posits that experience is related to the largest informationally integrated large-scale neuronal ensemble (Tononi, 2012; Oizumi et al., 2014), and that this is related to brain signal complexity (Tononi and Edelman, 1998).

Therefore, the re-experiencing phenomena and affective sequelae in combat-related PTSD may result from brain networks becoming "stuck" in configurations that reflect memories, emotions, and thoughts originating from the traumatizing experience. Our findings offer neurophysiological evidence for the long-held notion that PTSD is a disorder of fear learning and fear conditioning, whereby the re-experiencing of traumatic events arises from frequent reactivation of fear circuits. Increased con- 
a

$$
p<10^{-10} \text {, crossblock covariance }=60 \%
$$

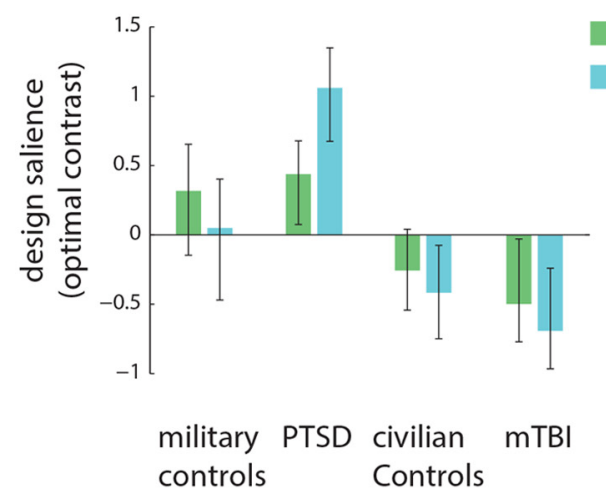

C

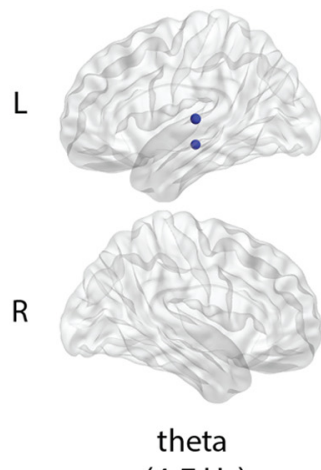

(4-7 Hz)

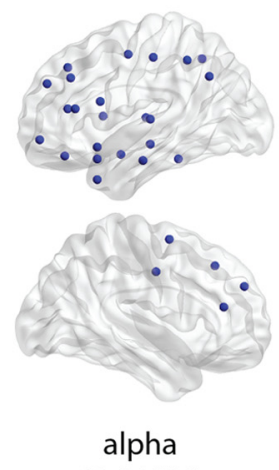

(8-14 Hz) resting 1

resting 2 b

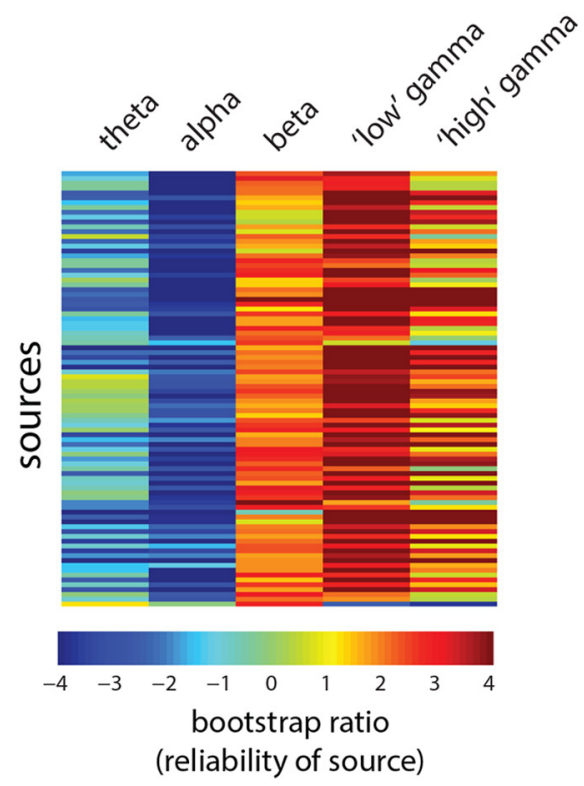

bootstrap ratios

- positive: express contrast in (a) as shown

- negative: express opposite contrast

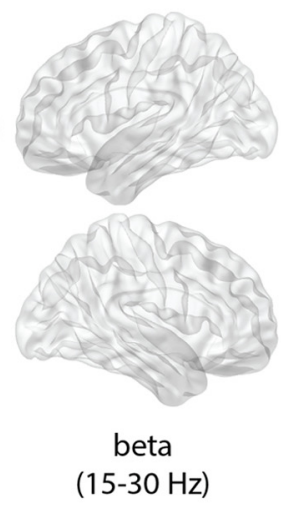

(15-30 Hz)
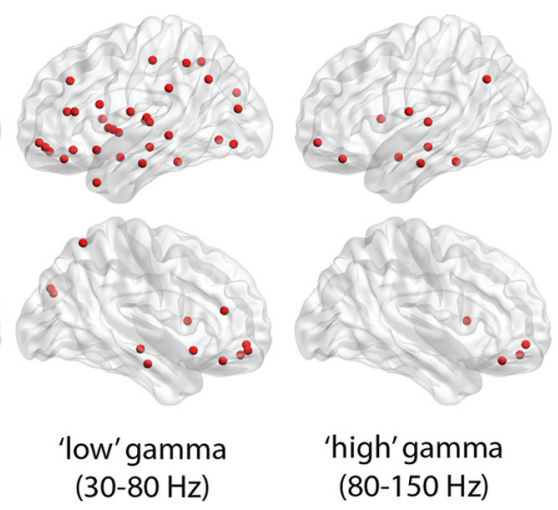

‘high' gamma

(80-150 Hz)

Figure 6. Oscillatory power: group differences. The dominant PLS latent variable, capturing the effect of group membership on local oscillatory power (measured by PSD) in multiple frequency bands. $\boldsymbol{a}$, The optimal combination of groups and conditions (contrast). Error bars represent bootstrap-estimated $95 \%$ confidence intervals. $\boldsymbol{b}$, Bootstrap ratios: a linear combination of sources, weighted by how reliably they contribute to the latent variable. For a given connection, a high-magnitude positive bootstrap ratio indicates that the source reliably expresses the contrast in $\boldsymbol{a}$. A high-magnitude negative bootstrap ratio indicates that the connection expresses the opposite contrast. c, Statistical maps showing networks of sources that reliably express the contrast in $\boldsymbol{a}$, as determined by bootstrapping (see Materials and Methods).

nectivity among temporal lobe structures, with a concomitant decrease in signal variability, suggests that these fear-related and memory-related circuits are effectively "locked" in certain configurations. This rigidity may prevent the exploration of alternative network states and configurations, leading to the core cognitive and affective symptoms of PTSD.

The implication of these findings is that the symptoms of PTSD may potentially be relieved by treatments that restore the natural variability in these subnetworks. Although the effects of pharmacologic intervention on connectivity and variability are not yet fully understood, several recent studies suggest the possibility that local signal variability may be modulated pharmacologically, with robust cognitive effects (Tagliazucchi et al., 2014; Garrett et al., 2015). For instance, Garrett et al. (2015) recently showed that dopamine agonists, such as D-amphetamine may boost signal variability and cognitive performance in older adults. The present results contribute to a growing literature showing that the brain's functional architecture and local dynamics are not just important markers of healthy and pathological cognitive function, but potential targets for therapeutic intervention as well.

Interestingly, the PSD analysis bore some topographic similarity to the wPLI analysis. In the alpha and high-gamma bands, sources that exhibit decreased/increased oscillatory power also participate in many weaker/stronger functional connections. Likewise, no significant effects are observed for either measure in the beta band. In theory, changes in phase synchrony do not necessarily have to accompany changes in local oscillatory power, yet in practice, the two are often found to be related (Singer, 1993). Computational models suggest that the power of local oscillations and their mutual synchrony could potentially be mediated by a number of anatomical and physiological characteris- 
tics, including coupling strength, propagation delays, and intrinsic dynamics (David and Friston, 2003; Zavaglia et al., 2008). In particular, synchronization among remote neural assemblies may at least partly contribute to oscillatory power in those assemblies (Singer, 1993).

In this context, the discrepancy between connectivity and oscillatory power in the low-gamma range $(30-80 \mathrm{~Hz})$ is salient. Increased power in this band is concomitant with decreased synchrony, suggesting that PTSD disrupts communication. Despite the increased prominence of $30-80 \mathrm{~Hz}$ rhythms, they appear to contribute less to global information transfer. Thus, reduced synchrony in the low gamma range may be as important to the PTSD phenotype as increased synchrony in the high gamma range (80$150 \mathrm{~Hz}$ ). The fact that synchrony is affected differentially in the two bands may indicate a gradual rebalancing of communication from lower to higher frequencies, resulting in the high-frequency hypersynchrony observed in the present study.

Our results and interpretations are also subject to several potential limitations. First, as with most naturalistic PTSD studies, the effects of exposure to trauma cannot be disentangled from potential biological predisposition to the disorder, nor from the effects of medications or other interventions and treatments. In the present PTSD sample, all individuals were taking evidencebased psychotropic medication, including SSRIs, SNRIs, and prazosin, an alpha blocker. The effects of conventional pharmacotherapy on global synchrony and signal variability are still not fully understood, which means that the effects of PTSD on these measures may be confounded by the administration of psychotropic medication. For instance, McCabe and Mishor (2011) found that administration of the SSRI citalopram reduces resting-state functional connectivity in a specific prefrontal circuit, while Schaefer et al. (2014) found that administration of escitalopram reduces intrinsic connectivity throughout the brain. These considerations highlight an important challenge going forward in human brain mapping and connectomics: namely, the need to understand the effect of commonly used medication on both traditional and novel measures of brain structure and function, in both healthy participants and clinical populations.

Second, we emphasize that contrasts between pre-trigger and post-trigger resting-state scans should be interpreted with caution. Although the scans were made before and after several cognitive tasks that included emotionally salient stimuli, differences between the two recordings do not necessarily reflect emotional triggering, or may only partly reflect emotional triggering. For example, these differences could also be due to order effects and to the deployment of other, nonemotional cognitive processes. Our results suggest that the confluence of these factors elicits a differential response in PTSD and control soldiers and that future research should aim to disentangle the contribution of affective and cognitive processes in this population.

In summary, our findings contribute to growing evidence that post-traumatic stress is a network-level disorder that affects multiple aspects of neural information processing, dynamics, and communication. By continuing to explore specific features, including functional connectivity and signal variability, it should become possible to further articulate the mechanisms underlying the disorder. Moreover, insight about neural information processing and communication dynamics gained from clinical populations may ultimately help us to further appreciate their importance in the context of healthy brain function as well.

\section{References}

American Psychiatric Association (2000) Diagnostic and statistical manual of mental disorders, $4^{\text {th }}$ edition, text revision. Arlington, VA: American Psychiatric Association.

Attal Y, Schwartz D (2013) Assessment of subcortical source localization using deep brain activity imaging model with minimum norm operators: a MEG study. PLoS One 8:e59856. CrossRef Medline

Balderston NL, Schultz DH, Baillet S, Helmstetter FJ (2013) How to detect amygdala activity with magnetoencephalography using source imaging. J Vis Exp 76. CrossRef Medline

Bardouille T, Ross B (2008) MEG imaging of sensorimotor areas using inter-trial coherence in vibrotacticle steady-state responses. NeuroImage 42:323-331. CrossRef Medline

Berman MG, Misic B, Buschkuehl M, Kross E, Deldin PJ, Peltier S, Churchill NW, Jaeggi SM, Vakorin V, McIntosh AR, Jonides J (2014) Does resting-state connectivity reflect depressive rumination? A tale of two analyses. Neuroimage 103:267-279. CrossRef Medline

Bish JP, Martin T, Houck J, Ilmoniemi RJ, Tesche C (2004) Phase shift detection in thalamocortical oscillations using magnetoencephalography in humans. Neurosci Lett 362:48-52. CrossRef Medline

Boersma M, Kemner C, de Reus MA, Collin G, Snijders TM, Hofman D, Buitelaar JK, Stam CJ, van den Heuvel MP (2013) Disrupted functional brain networks in autistic toddlers. Brain Connect 3:41-49. CrossRef Medline

Bremner JD, Vythilingam M, Vermetten E, Southwick SM, McGlashan T, Nazeer A, Khan S, Vaccarino LV, Soufer R, Garg PK, Ng CK, Staib LH, Duncan JS, Charney DS (2003) MRI and PET study of deficits in hippocampal structure and function in women with childhood sexual abuse and posttraumatic stress disorder. Am J Psychiat 160:924-932. CrossRef Medline

Brookes MJ, Hall EL, Robson SE, Price D, Palaniyappan L, Liddle EB, Liddle PF, Robinson SE, Morris PG (2015) Complexity measures in magnetoencephalography: measuring "disorder" in schizophrenia. PLoS One 10: e0120991. CrossRef Medline

Brown VM, LaBar KS, Haswell CC, Gold AL, Gold AL, McCarthy G, Morey RA (2014) Altered resting-state functional connectivity of basolateral and centromedial amygdala complexes in posttraumatic stress disorder. Neuropsychopharmacology 39:351-359. CrossRef Medline

Bryant R (2011) Post-traumatic stress disorder vs traumatic brain injury. Dialogues Clin Neurosci 13:251-262. Medline

Catarino A, Churches O, Baron-Cohen S, Andrade A, Ring H (2011) Atypical EEG complexity in autism spectrum conditions: a multiscale entropy analysis. Clin Neurophysiol 122:2375-2383. CrossRef Medline

Cornwell BR, Baas JM, Johnson L, Holroyd T, Carver FW, Lissek S, Grillon C (2007) Neural responses to auditory stimulus deviance under threat of electric shock revealed by spatially-filtered magnetoencephalography. NeuroImage 37:282-289. CrossRef Medline

Cornwell BR, Johnson LL, Holroyd T, Carver FW, Grillon C (2008a) Human hippocampal and parahippocampal theta during goal-directed spatial navigation predicts performance on a virtual Morris water maze. J Neurosci 28:5983-5990. CrossRef Medline

Cornwell BR, Carver FW, Coppola R, Johnson L, Alvarez R, Grillon C (2008b) Evoked amygdala responses to negative faces revealed by adaptive MEG beamformers. Brain Res 1244:103-112. CrossRef Medline

Cornwell BR, Salvadore G, Colon-Rosario V, Latov DR, Holroyd T, Carver FW, Coppola R, Manji HK, Zarate CA Jr, Grillon C (2010) Abnormal hippocampal functioning and impaired spatial navigation in depressed individuals: evidence from whole-head magnetoencephalography. Am J Psychiatry 167:836-844. CrossRef Medline

Costa M, Goldberger AL, Peng CK (2002) Multiscale entropy analysis of complex physiologic time series. Phys Rev Lett 89:068102. CrossRef Medline

Costa M, Goldberger AL, Peng CK (2005) Multiscale entropy analysis of biological signals. Phys Rev E Stat Nonlin Soft Matter Phys 71:021906. CrossRef Medline

David O, Friston KJ (2003) A neural mass model for MEG/EEG coupling and neuronal dynamics. Neuroimage 20:1743-1755. CrossRef Medline

Deco G, Jirsa V, McIntosh AR, Sporns O, Kötter R (2009) Key role of coupling, delay, and noise in resting brain fluctuations. Proc Natl Acad Sci U S A 106:10302-10307. CrossRef Medline

Deco G, Jirsa VK, McIntosh AR (2013) Resting brains never rest: computa- 
tional insights into potential cognitive architectures. Trends Neurosci 36:268-274. CrossRef Medline

Dimitriadis SI, Laskaris NA, Simos PG, Micheloyannis S, Fletcher JM, Rezaie R, Papanicolaou AC (2013) Altered temporal correlations in resting state-connectivity fluctuations in children with reading difficulties detected via MEG. NeuroImage 83:307-317. CrossRef Medline

Dunkley BT, Doesburg SM, Sedge PA, Grodecki RJ, Shek PN, Pang EW, Taylor MJ (2014) Resting-state hippocampal connectivity correlates with symptom severity in post-traumatic stress disorder. Neuroimage Clin 5:377-384. CrossRef Medline

Efron B, Tibshirani R (1986) Bootstrap methods for standard errors, confidence intervals, and other measures of statistical accuracy. Stat Sci 1:5475. CrossRef

Engdahl B, Leuthold AC, Tan H-RM, Lewis SM, Winskowski AM, Dikel TN, Georgopoulos AP (2010) Post-traumatic stress disorder: a right temporal lobe syndrome? J Neural Eng 7:066005. CrossRef Medline

Etkin A, Wager TD (2007) Functional neuroimaging of anxiety: a metaanalysis of emotional processing in PTSD, social anxiety disorder, and specific phobia. Am J Psychiat 164:1476-1488. CrossRef Medline

Felmingham K, Williams LM, Kemp AH, Liddell B, Falconer E, Peduto A, Bryant R (2010) Neural responses to masked fear faces: sex differences and trauma exposure in posttraumatic stress disorder. J Abnorm Psychol 119:241-247. CrossRef Medline

Friston KJ (1994) Functional and effective connectivity in neuroimaging: a synthesis. Hum Brain Mapp 2:56-78. CrossRef

Garber BG, Zamorski MA, Jetly R (2012) Mental health of Canadian Forces members while on deployment to Afghanistan. Can J Psychiat 57:736744. Medline

Garrett DD, Kovacevic N, McIntosh AR, Grady CL (2010) Blood oxygen level-dependent signal variability is more than just noise. J Neurosci 30: 4914-4921. CrossRef Medline

Garrett DD, Kovacevic N, McIntosh AR, Grady CL (2011) The importance of being variable. J Neurosci 31:4496-4503. CrossRef Medline

Garrett DD, Samanez-Larkin GR, MacDonald SW, Lindenberger U, McIntosh AR, Grady CL (2013) Moment-to-moment brain signal variability: a next frontier in human brain mapping? Neurosci Biobehav Rev 37:610624. CrossRef Medline

Garrett DD, McIntosh AR, Grady CL (2014) Brain signal variability is parametrically modifiable. Cereb Cortex 24:2931-2940. CrossRef Medline

Garrett DD, Nagel IE, Preuschhof C, Burzynska AZ, Marchner J, Wiegert S, Jungehülsing GJ, Nyberg L, Villringer A, Li SC, Heekeren HR, Bäckman L, Lindenberger U (2015) Amphetamine modulates brain signal variability and working memory in younger and older adults. Proc Natl Acad Sci U S A 112:7593-7598. CrossRef Medline

Georgopoulos AP, Tan HM, Lewis S, Leuthold A, Winskowski A, Lynch J, Engdahl B (2010) The synchronous neural interactions test as a functional neuromarker for post-traumatic stress disorder (PTSD): a robust classification method based on the bootstrap. J Neural Eng 7:016011. CrossRef Medline

Hamada Y, Sugino K, Kado H, Suzuki R (2004) Magnetic fields in the human hippocampal area evoked by a somatosensory oddball task. Hippocampus 14:426-433. CrossRef Medline

Heisz JJ, Shedden JM, McIntosh AR (2012) Relating brain signal variability to knowledge representation. Neuroimage 63:1384-1392. CrossRef Medline

Hung Y, Smith ML, Taylor MJ (2012) Development of ACC-amygdala activations in processing unattended fear. NeuroImage 60:545-552. CrossRef Medline

Ibrahim GM, Cassel D, Morgan BR, Smith ML, Otsubo H, Ochi A, Taylor M, Rutka JT, Snead OC 3rd, Doesburg S (2014) Resilience of developing brain networks to interictal epileptiform discharges is associated with cognitive outcome. Brain 137:2690-2702. CrossRef Medline

James LM, Engdahl BE, Leuthold AC, Lewis SM, Van Kampen E, Georgopoulos AP (2013) Neural network modulation by trauma as a marker of resilience: differences between veterans with posttraumatic stress disorder and resilient controls. JAMA Psychiatry 70:410-418. CrossRef Medline

Kasai K, Yamasue H, Gilbertson MW, Shenton ME, Rauch SL, Pitman RK (2008) Evidence for acquired pregenual anterior cingulate gray matter loss from a twin study of combat-related posttraumatic stress disorder. Biol Psychiatry 63:550-556. Medline

Keane TM, Kolb LC, Kaloupek DG, Orr SP, Blanchard EB, Thomas RG, Hsieh FY, Lavori PW (1998) Utility of psychophysiology measurement in the diagnosis of posttraumatic stress disorder: Results from a department of veteran's affairs cooperative study. J Consult Clin Psychol 66:914-923. CrossRef Medline

Kirsch P, Achenbach C, Kirsch M, Heinzmann M, Schienle A, Vaitl D (2003) Cerebellar and hippocampal activation during eyeblink conditioning depends on the experimental paradigm: a MEG study. Neural Plast 10:291301. CrossRef Medline

Kitayama N, Vaccarino V, Kutner M, Weiss P, Bremner JD (2005) Magnetic resonance imaging (MRI) measurement of hippocampal volume in posttraumatic stress disorder: a meta-analysis. J Affect Disorders 88:79-86. CrossRef Medline

Kitayama N, Quinn S, Bremner JD (2006) Smaller volume of anterior cingulate cortex in abuse-related posttraumatic stress disorder. J Affect Disorders 90:171-174. CrossRef Medline

Kolassa IT, Wienbruch C, Neuner F, Schauer M, Ruf M, Odenwald M, Elbert $\mathrm{T}$ (2007) Altered oscillatory brain dynamics after repeated traumatic stress. BMC Psychiatry 7:56. CrossRef Medline

Lau TM, Gwin JT, McDowell KG, Ferris DP (2012) Weighted phase lag index stability as an artifact resistant measure to detect cognitive EEG activity during locomotion. J Neuroeng Rehabil 9:47. CrossRef Medline

Luo Q, Holroyd T, Jones M, Hendler T, Blair J (2007) Neural dynamics for facial threat processing as revealed by gamma band synchronization using MEG. NeuroImage 34:839-847. CrossRef Medline

McCabe C, Mishor Z (2011) Antidepressant medications reduce subcorticalcortical resting-state functional connectivity in healthy volunteers. NeuroImage 57:1317-1323. CrossRef Medline

McIntosh AR, Lobaugh NJ (2004) Partial least squares analysis of neuroimaging data: applications and advances. Neuroimage 23:S250-S263. CrossRef Medline

McIntosh AR, Mišić B (2013) Multivariate statistical analyses for neuroimaging data. Annu Rev Psychol 64:499-525. CrossRef Medline

McIntosh AR, Kovacevic N, Itier RJ (2008) Increased brain signal variability accompanies lower behavioral variability in development. PLoS Comput Biol 4:e1000106. CrossRef Medline

McIntosh AR, Vakorin V, Kovacevic N, Wang H, Diaconescu A, Protzner AB (2014) Spatiotemporal dependency of age-related changes in brain signal variability. Cereb Cortex 24:1806-1817. CrossRef Medline

Mills T, Lalancette M, Moses SN, Taylor MJ, Quraan MA (2012) Techniques for detection and localization of weak hippocampal and medial frontal sources using beamformers in MEG. Brain Topogr 25:248-263. CrossRef Medline

Mišić B., Mills T, Taylor MJ, McIntosh AR (2010) Brain noise is taskdependent and region-specific. J Neurophysiol 104:2667-2676. CrossRef Medline

Mišić B, Vakorin VA, Paus T, McIntosh AR (2011) Functional embedding predicts the variability of neural activity. Front Syst Neurosci 5:90. CrossRef Medline

Mišić B, Fatima Z, Askren MK, Buschkuehl M, Churchill N, Cimprich B, Deldin PJ, Jaeggi S, Jung M, Korostil M, Kross E, Krpan KM, Peltier S, Reuter-Lorenz PA, Strother SC, Jonides J, McIntosh AR, Berman MG (2014) The functional connectivity landscape of the human brain. PLoS One 9:e111007. CrossRef Medline

Mišić B, Doesburg SM, Fatima Z, Vidal J, Vakorin VA, Taylor MJ, McIntosh AR (2015) Coordinated information generation and mental flexibility: large-scale network disruption in children with autism. Cereb Cortex 25:2815-2827. CrossRef Medline

Mizuno T, Takahashi T, Cho RY, Kikuchi M, Murata T, Takahashi K, Wada Y (2010) Assessment of EEG dynamical complexity in Alzheimer disease using multiscale entropy. Clin Neurophysiol 121:1438-1446. CrossRef Medline

Muthukumaraswamy SD (2013) High-frequency brain activity and muscle artifacts in MEG/EEG: a review and recommendations. Front Hum Neurosci 7:138. CrossRef Medline

Oizumi M, Albantakis L, Tononi G (2014) From the phenomenology to the mechanisms of consciousness: integrated information theory 3.0. PLoS Comput Biol 10:e1003588. CrossRef Medline

Orr SP, Roth WT (2000) Psychophysiological assessment: clinical applications for PTSD. J Affect Disorders 61:225-240. CrossRef Medline

Pitman RK, Orr SP, Forgue DF, de Jong JB, Claiborn JM (1987) Psychophysiologic assessment of posttraumatic stress disorder imagery in Vietnam combat veterans. Arch Gen Psychiatry 44:970-975. CrossRef Medline 
Pitman RK, Rasmusson AM, Koenen KC, Shin LM, Orr SP, Gilbertson MW, Milad MR, Liberzon I (2012) Biological studies of post-traumatic stress disorder. Nat Rev Neurosci 13:769-787. CrossRef Medline

Pole N (2007) The psychophysiology of posttraumatic stress disorder: a meta-analysis. Psychol Bull 133:725-746. CrossRef Medline

Quraan MA, Cheyne D (2010) Reconstruction of correlated brain activity with adaptive spatial filters in MEG. Neuroimage 49:2387-2400. CrossRef Medline

Quraan MA, Moses SN, Hung Y, Mills T, Taylor MJ (2011) Detection and localization of hippocampal activity using beamformers with MEG: a detailed investigation using simulations and empirical data. Hum Brain Mapp 32:812-827. CrossRef Medline

Rabinak CA, Angstadt M, Welsh RC, Kenndy AE, Lyubkin M, Martis B, Phan KL (2011) Altered amygdala resting-state functional connectivity in post-traumatic stress disorder. Front Psychiatry 2:62. CrossRef Medline

Raja Beharelle A, Kovačević N, McIntosh A, Levine B (2012) Brain signal variability relates to stability of behavior after recovery from diffuse brain injury. Neuroimage 60:1528-1537. CrossRef Medline

Richman J, Moorman J (2000) Physiological time-series analysis using approximate entropy and sample entropy. Am J Physiol Heart Circ Physiol 47:H2039-H2049. Medline

Schaefer A, Burmann I, Regenthal R, Arélin K, Barth C, Pampel A, Villringer A, Margulies DS, Sacher J (2014) Serotonergic modulation of intrinsic functional connectivity. Curr Biol 24:2314-2318. CrossRef Medline

Shin LM, Orr SP, Carson MA, Rauch SL, Macklin ML, Lasko NB, Peters PM, Metzger LJ, Dougherty DD, Cannistraro PA, Alpert NM, Fischman AJ, Pitman RK (2004) Regional cerebral blood flow in the amygdala and medial prefrontalcortex during traumatic imagery in male and female Vietnam veterans with PTSD. Arch Gen Psychiat 61:168-176. CrossRef Medline

Singer W (1993) Synchronization of cortical activity and its putative role in information processing and learning. Annu Rev Physiol 55:349-374. CrossRef Medline

Small M, Tse C (2004) Optimal embedding parameters: a modelling paradigm. Physica D Nonlin Phenom 194:283-296. CrossRef

Tagliazucchi E, Carhart-Harris R, Leech R, Nutt D, Chialvo DR (2014) Enhanced repertoire of brain dynamical states during the psychedelic experience. Hum Brain Mapp 35:5442-5456. CrossRef Medline
Takahashi T, Cho RY, Mizuno T, Kikuchi M, Murata T, Takahashi K, Wada Y (2010) Antipsychotics reverse abnormal EEG complexity in drug-naïve schizophrenia: a multiscale entropy analysis. Neuroimage 51:173-182. CrossRef Medline

Tononi G (2012) Integrated information theory of consciousness: an updated account. Arch Ital Biol 150:56-90. CrossRef Medline

Tononi G, Edelman GM (1998) Consciousness and complexity. Science 282:1846-1851. CrossRef Medline

Tzourio-Mazoyer N, Landeau B, Papathanassiou D, Crivello F, Etard O, Delcroix N, Mazoyer B, Joliot M (2002) Automated anatomical labeling of activations in SPM using a macroscopic anatomical parcellation of the MNI MRI single-subject brain. Neuroimage 15:273-289. CrossRef Medline

Vakorin VA, Lippé S, McIntosh AR (2011) Variability of brain signals processed locally transforms into higher connectivity with brain development. J Neurosci 31:6405-6413. CrossRef Medline

Vinck M, Oostenveld R, van Wingerden M, Battaglia F, Pennartz CM (2011) An improved index of phase-synchronization for electrophysiological data in the presence of volume-conduction, noise and sample-size bias. Neuroimage 55:1548-1565. CrossRef Medline

Yang AC, Huang CC, Yeh HL, Liu ME, Hong CJ, Tu PC, Chen JF, Huang NE, Peng CK, Lin CP, Tsai SJ (2013) Complexity of spontaneous BOLD activity in default mode network is correlated with cognitive function in normal male elderly: a multiscale entropy analysis. Neurobiol Aging 34: 428-438. CrossRef Medline

Ye AX, Leung RC, Schäfer CB, Taylor MJ, Doesburg SM (2014) Atypical resting synchrony in autism spectrum disorder. Hum Brain Mapp 35: 6049-6066. CrossRef Medline

Zavaglia M, Astolfi L, Babiloni F, Ursino M (2008) The effect of connectivity on EEG rhythms, power spectral density and coherence among coupled neural populations: analysis with a neural mass model. IEEE Trans Biomed Eng 55:69-77. CrossRef Medline

Zhou Y, Wang Z, Qin LD, Wan JQ, Sun YW, Su SS, Ding WN, Xu JR (2012) Early altered resting-state functional connectivity predicts the severity of post-traumatic stress disorder symptoms in acutely traumatized subjects. PLoS One 7:e46833. CrossRef Medline 